\title{
Peritoneal Surface
}

National Cancer Institute

\section{Source}

National Cancer Institute. Peritoneal Surface. NCI Thesaurus. Code C160423.

The outer layer of the serous membrane that lines the abdominal cavity. 